\title{
( EDITOR'S CHOICE \\ MRI-guided STN DBS in Parkinson's disease without microelectrode recording: efficacy and safety
}

\author{
T Foltynie, ${ }^{1}$ L Zrinzo, ${ }^{1,2}$ I Martinez-Torres, ${ }^{3}$ E Tripoliti, ${ }^{1}$ E Petersen, ${ }^{4}$ E Holl, ${ }^{1,5}$ \\ | Aviles-Olmos, ${ }^{1}$ M Jahanshahi, ${ }^{1}$ M Hariz, ${ }^{1,6}$ P Limousin ${ }^{1}$
}

\begin{abstract}
See Editorial Commentary, p 356

${ }^{1}$ Unit of Functional

Neurosurgery, Sobell

Department of Motor

Neuroscience, UCL Institute of

Neurology, Queen Square,

London, UK

${ }^{2}$ Victor Horsley Department of Neurosurgery, National Hospital for Neurology and

Neurosurgery, Queen Square, London, UK

${ }^{3}$ Department of Neurology, Hospital La Fe, Valencia, Spain ${ }^{4}$ Department of Neurosurgery, University of Texas,

Southwestern, Dallas, Texas, USA

${ }^{5}$ Department of Neurosurgery, Medical University, Graz, Austria ${ }^{6}$ Department of Neurosurgery, University Hospital, Umea, Sweden
\end{abstract}

\section{Correspondence to}

Thomas Foltynie, Unit of Functional Neurosurgery, Sobell Department of Motor Neuroscience, Box 146 National Hospital for Neurology and Neurosurgery, Queen Square, London WC1N 3BG, UK; t.foltynie@ion.ucl.ac.uk

Received 12 January 2010 Revised 7 April 2010 Revised 12 April 2010 Published Online First 22 June 2010

\section{ABSTRACT}

Deep brain stimulation (DBS) of the subthalamic nucleus (STN) is a commonly employed therapeutic procedure for patients with Parkinson's disease uncontrolled by medical therapies. This series describes the outcomes of 79 consecutive patients that underwent bilateral STN DBS at the National Hospital for Neurology and Neurosurgery between November 2002 and November 2008 using an MRl-guided surgical technique without microelectrode recording. Patients underwent immediate postoperative stereotactic MR imaging. The mean (SD) error in electrode placement was $1.3(0.6) \mathrm{mm}$. There were no haemorrhagic complications. At a median follow-up period of 12 months, there was a mean improvement in the off-medication motor part of the Unified Parkinson's Disease Rating Scale (UPDRS III) of 27.7 points (SD 13.8) equivalent to a mean improvement of $52 \%(p<0.0001)$. In addition, there were significant improvements in dyskinesia duration, disability and pain, with a mean reduction in on-medication dyskinesia severity (sum of dyskinesia duration, disability and pain from UPDRS IV) from 3.15 (SD 2.33) pre-operatively, to 1.56 (SD 1.92) post-operatively $(p=0.0001)$. Quality of life improved by a mean of 5.5 points (median 7.9 points, SD 17.3) on the Parkinson's disease Questionnaire 39 summary index. This series confirms that image-guided STN DBS without microelectrode recording can lead to substantial improvements in motor disability of wellselected PD patients with accompanying improvements in quality of life and most importantly, with very low morbidity.

"In clinical practice, brain imaging can now be divided in two parts: the diagnostic neuroradiology and the preoperative stereotactic localisation procedure. The latter is part of the therapeutic procedure. It is the surgeon's responsibility and should be closely integrated with the operation." Lars Leksell ${ }^{1}$.

Deep brain stimulation (DBS) of the subthalamic nucleus (STN) is an accepted surgical treatment for symptoms of Parkinson's disease (PD) inadequately controlled by medical therapies. ${ }^{2} 3 \mathrm{PD}$ is a chronic neurodegenerative disease for which many medical treatments are available; therefore, interventions such as STN DBS that are neither life-saving nor disease-modifying but are aimed at improving quality of life must meet the very highest standards of safety. Major risks associated with the surgical procedure include intra-cerebral haemorrhage and infection of the implanted material, while adverse effects of stimulation are presumably related to stimulation of non-motor regions within or outside of the STN. ${ }^{4}$ Factors that may potentially improve safety and/or efficacy of the procedure for individual patients and for the group as a whole are of utmost importance.

The majority of centres currently use microelectrode recording (MER) from individual neurons to identify the characteristic neuronal firing patterns or "physiological signature" of STN neurons during surgery. Since the introduction and widespread adoption of STN DBS for PD, there has been a paucity of reports evaluating this procedure when it is performed without MER. ${ }^{6}$ This study presents efficacy and safety outcomes of a large consecutive prospective series of PD patients $(n=79)$ treated with STN DBS in a single centre, using a standardised surgical technique based on individual MRI-guided targeting without MER.

\section{MATERIAL AND METHODS \\ Patients}

Seventy-nine consecutive patients underwent STN DBS at the National Hospital for Neurology and Neurosurgery between November 2002 and November 2008. All patients met UK Brain Bank criteria for the diagnosis of $\mathrm{PD}$ and suffered from disabling motor complications of the illness despite optimal medical treatment. Before deciding on suitability for surgery, a brain MRI was obtained to exclude patients with advanced brain atrophy, white matter changes or other abnormality contraindicating surgery. Baseline neuropsychological tests identified patients with significant cognitive impairment and L-dopa equivalent doses calculated for each patient. ${ }^{7}$ An L-dopa challenge was performed to confirm drug responsiveness using the motor part of the Unified Parkinson's Disease Rating Scale (UPDRS III). A numerical measure of L-dopa response was derived as follows: (Off UPDRS III On UPDRS III score)/Off UPDRS III $\times 100$. The offmedication state was practically defined as an overnight period free of medication. Speech was assessed using the Assessment of Intelligibility for Dysarthric Speech. ${ }^{8}$ Patients were asked to complete the Parkinson's Disease Questionnaire 39 scale (PDO39). ${ }^{9}$ The final decision regarding the appropriateness of STN DBS surgery for each patient was taken during a joint meeting of patient, immediate family, neurologist(s) and neurosurgeon(s).

\section{Image acquisition and surgical procedure}

Surgery was usually performed under local anaesthesia, in the off-medication condition, to allow clinical evaluation during electrode placement. If the patient was unable to tolerate prolonged periods off medication, surgery was performed under general anaesthesia $(n=12)$. The STN was 
visualised in each patient using specifically selected pre-operative stereotactic MRI sequences ${ }^{10} 11$ following Leksell frame attachment (Elekta Instrument AB, Stockholm). Target selection for placement of the deepest contact was performed at the level of maximal rubral diameter (around $5 \mathrm{~mm}$ below the AC PC plane) using commercially available planning software (FrameLink, Medtronic, Minneapolis). The STN was visualised as the hypointense signal lateral to the red nucleus. The entry point was defined at or behind the coronal suture to ensure a trajectory that would avoid sulci and the ventricular system. The exact entry and target point were subsequently modified to maintain a parenchymal trajectory while maximising the length of the trajectory within the visible STN hypointensity from the AC-PC to target level. ${ }^{12} 13$ This was best achieved by reformatting images along the planned trajectory. As a result, the final target point was often located a couple of millimetres posterolateral to the target point described by Bejjani et al ${ }^{14}$ (figure 1). Since the sensorimotor STN is thought to occupy the supero-postero-lateral portion of the nucleus, this target point
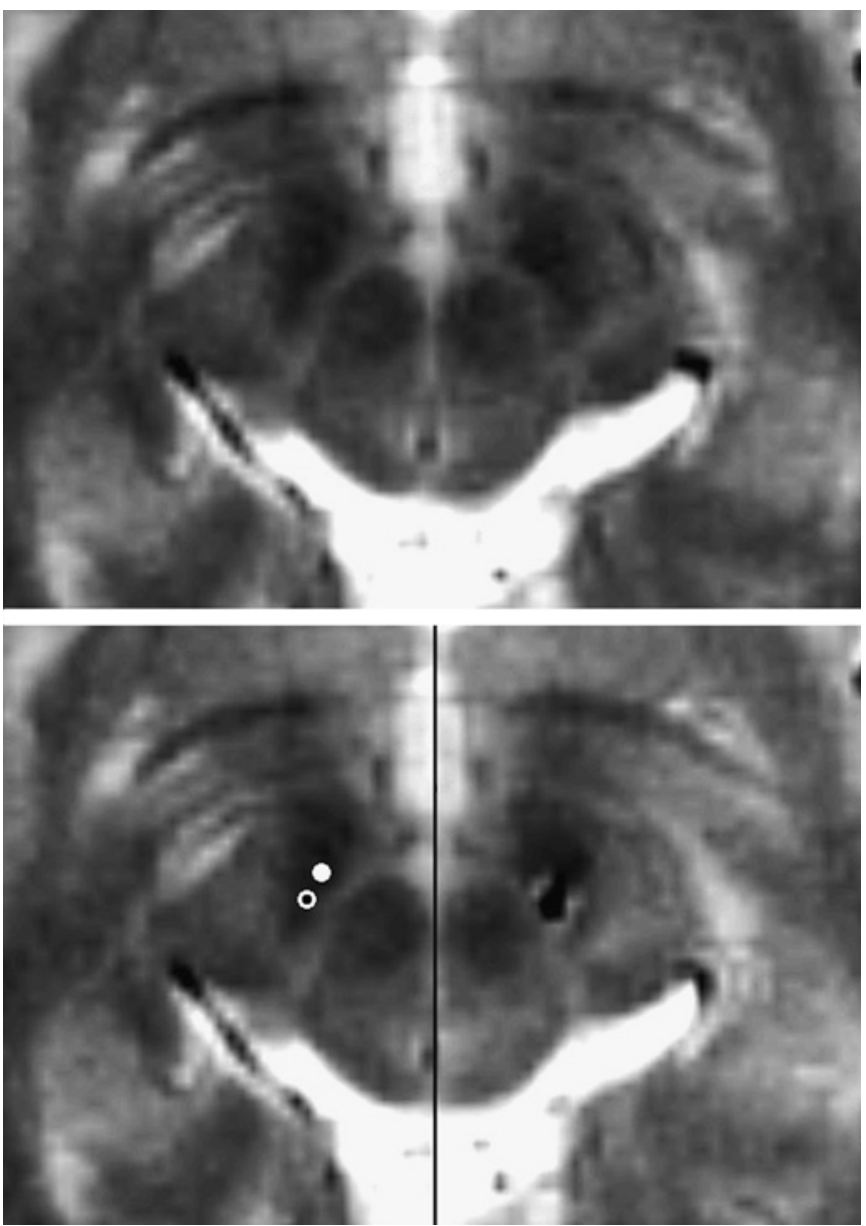

Figure 1 Top panel: Preoperative stereotactic T2-weighted axial MRI (1.5T, 2 mm thickness, no gap, TR 3500, TE 90.9) at the level of maximal rubral diameter (around $5 \mathrm{~mm}$ below the AC-PC plane). The subthalamic nucleus (STN) was visualised as the hypointense signal lateral to the red nucleus. Bottom left panel: The entry and target point were selected to maintain a parenchymal trajectory while maximising the length of the trajectory within the visible STN hypointensity from the $\mathrm{AC}-\mathrm{PC}$ to target level. As a result, the final target point (open circle) was typically located $2.5 \mathrm{~mm}$ posterolateral to the target point originally described by Bejjani et al (solid circle). Bottom right panel: Postoperative stereotactic T2-weighted axial MRI at equivalent level revealing electrode artefact at intended target. may bring the electrode trajectory closer to the desired functional target. ${ }^{15}$

During surgery, brain shift was avoided in several ways. Minimal CSF loss was achieved by placing the 14-mm burr hole and $3-4 \mathrm{~mm}$ small dural opening on a gyrus rather than a sulcus, flooding the burr hole with saline irrigation after dural opening, limiting the time from dural opening to final DBS electrode implantation and sealing the dural defect with fibrin glue as soon as the DBS electrode was in situ and before test stimulation/and or local field potential recording. Performing surgery in a similar position to that adopted during image acquisition, with only slight head-up tilt to encourage venous drainage, may further limit shift by minimising postural movement of intracranial structures.

Dynamic impedance monitoring was performed while introducing a 1.5- or 2.2-mm diameter, blunt-tip radiofrequency (RF) electrode to the target (Leksell RF electrodes, Elekta, Stockholm). Great care was taken to avoid electrode deviation by contact with the burr hole or dural edges. A sharp tip probe would theoretically result in less brain deformation; however, the authors avoid this technique in view of the potential penetration, rather than displacement, of intraparenchymal vessels and resulting haemorrhage. After withdrawal of the RF electrode, a quadripolar DBS electrode (Model 3389 DBS lead, Medtronic ${ }^{\circledR}$, Minneapolis) was soft-passed down the same track. The depth of implantation of the deepest electrode was controlled by placing a depth stop a defined length along the electrode shaft. In those patients undergoing surgery under local anaesthesia, symptoms were assessed for the presence of a micro-lesion introduction effect. Monopolar stimulation through the contacts of the DBS electrode was then sequentially performed to assess for additional therapeutic effect and/or the presence of side effects ( $\sim 10 \mathrm{~min}$ per side). The electrodes were secured in place with a skull fixation device (Medtronic burrhole cap or Stimloc device). Immediately following implantation of the DBS leads, all patients had a stereotactic MRI scan to confirm the electrode positions before implantation of the pulse generator. The perpendicular scalar (Euclidean) distance between the intended MRI target and the actual position of the implanted electrode was calculated on the immediate postoperative stereotactic MRI for each patient. The surgery was not considered to be finished until the post-operative imaging had confirmed acceptable placement of the electrodes. Prophylactic systemic antibiotics (Cefuroxime $1.5 \mathrm{~g}$ ) were administered intraoperatively and three more times during the following $24 \mathrm{~h}$. Frame fixation and imaging took approximately 45 min with an additional 30-45 min for stereotactic calculations. The typical duration of bilateral electrode implantation was $2 \mathrm{~h}$ for surgery under general anaesthesia and $3 \mathrm{~h}$ under local anaesthesia. All adverse events were recorded immediately post-operatively and during subsequent follow-up assessments.

\section{Follow-up}

Selection of the optimal stimulation parameters was based on the acute clinical response to stimulation during the first postoperative weeks, with further adjustment of parameters as required, at follow-up visits typically at 1, 3, 6 and 12 months. To ensure optimal stimulation parameters, all patients underwent off- and on-medication assessments at their 6-12 months post-operative visit and then annually thereafter, using the UPDRS scale. Patients completed post-operative PDO39 qualityof-life scales and neuropsychological assessments at their 6-12month follow-up visit, and follow-up evaluation of speech was performed in all patients after 2004 . 


\section{Data presentation and analysis}

The presentation of clinical outcome data includes the median, the mean and the range of outcomes. Comparisons of baseline and post-operative UPDRS and PDQ39 scores were performed using two-sided sign tests to avoid assumptions regarding data distribution. The motor response to DBS was calculated in two ways:

1. Percentage improvement in UPDRS III motor score from baseline to follow-up in the absence of medication=(Baseline off-med score)-(Post-operative off-med ON-stim score)/ (Baseline off-med score) $\times 100$.

2. Percentage improvement in UPDRS III motor score by turning stimulation $\mathrm{ON}$ at follow-up assessment in the absence of medication $=$ (Post-operative off-med, OFF-stim score)-(Post-operative off-med, ON-stim score)/(Post operative off-med, OFF-stim score) $\times 100$.

Imputation of data was performed among eight patients who requested not to be assessed in post-operative off-med, OFF-stim condition, as equal to baseline off-medication score. Composite sub-scores were derived from the sum of items 32-34 for total dyskinesia severity.

\section{RESULTS}

Demographic data for the 79 consecutive patients are presented in table 1.

Two patients had undergone unilateral pallidotomy before their initial consultations with us. In one of the 79 patients, the procedure was abandoned because of prolonged superficial bleeding from a cortical vein, and the consequent CSF leakage resulted in brain shift away from the skull. A decision was taken not to implant the permanent electrode after haemostasis was secured. Post-operative recovery was uneventful with no evidence of haemorrhage on postoperative imaging.

The remaining patients all underwent bilateral STN DBS, 77 during the same operating session. One patient had an unplanned staged bilateral procedure because of a complex partial seizure that followed the insertion of the first electrode. Following surgery, two patients did not have follow-up assessments because of (1) encephalopathy of unknown origin (presumed to be allergic) following electrode implantation requiring removal of all DBS hardware a few days later and (2) death from previously undiagnosed asymptomatic carcinoma 9 months following surgery. The remaining 76 patients all underwent formal re-evaluation of PD severity after at least 6 months of post-operative follow-up. Where patients had multiple follow-up assessments available, data were used from the assessment closest to the first anniversary of their surgery (median 12 months, mean 14 months (range 6-36 months).

All electrodes were implanted by means of a single brain penetration, except one electrode where two passes were needed. The median perpendicular targeting error between intended stereotactic coordinates and electrode trajectory, calculated from post-operative stereotactic $\mathrm{MR}$ images, was $1.3 \mathrm{~mm}$ (mean $1.3 \mathrm{~mm}$, SD 0.6, range 0 to $2.7 \mathrm{~mm}$ ). An example of one of our

Table 1 Demographic data of patients undergoing bilateral STN DBS

\begin{tabular}{ll}
\hline & Median (Mean, SD, Range) \\
\hline Sex distribution & 49 men, 30 women \\
Age at surgery & 58.9 years, $(57.3,7.7,34.5-70.2)$ \\
Duration of PD symptoms & 11.5 years, $(13.4,7.0,3.8-42.2)$ \\
L-dopa equivalent dose & $1620 \mathrm{mg}$ per day $(1620,641,0-3260)$ \\
First degree relative diagnosed with PD & $12 / 79(15 \%)$ \\
\hline
\end{tabular}

patients' post operative stereotactic MRI scans is shown in figure 1. The L-dopa equivalent dose at follow-up was reduced by a mean of $633 \mathrm{mg}(39 \%)$. The mean stimulation parameters at follow-up were Left STN 3.0 V, $60 \mu \mathrm{s}, 139 \mathrm{~Hz}$; Right STN 3.0 V, $62 \mu \mathrm{s}, 139 \mathrm{~Hz}$. Bipolar stimulation was used in 3/152 electrodes, monopolar stimulation for the remainder.

\section{UPDRS}

After a median follow-up time of 12 months, the median improvement in UPDRS III comparing baseline off-medication scores to follow-up off-medication, $\mathrm{ON}$-stimulation scores was $56 \%$ (mean 52\%, p $<0.0001$; see table 2).

There was no significant change in UPDRS III on-medication score. Comparison of baseline off-medication scores with followup off-medication, OFF-stimulation scores shows a median decline of 1.5 UPDRS points (mean 3 points, range 28 points improvement to 35 points deterioration). Significant improvements were seen following STN DBS for UPDRS IV (complications of L-dopa treatment) as shown in table 3. The median total dyskinesia severity score (sum of dyskinesia duration, disability and pain) was 3 pre-operatively (mean 3.15, SD 2.33) and 1 post-operatively (mean $1.56 \mathrm{SD} 1.92$ ) equivalent to a reduction of $55 \%(\mathrm{p}<0.0001)$

\section{PD039}

Completed PDQ39 quality-of-life data were available from both pre- and post-operative time periods in a subgroup of 49 consecutive individuals(table 4; these data were not routinely collected for the first 1 to 2 years of the period studied). For these individuals, DBS led to a median improvement of 7.9 points (mean 5.5 points, $\mathrm{p}=0.04$ ) in the PDQ39 summary index, equivalent to an $18 \%$ improvement. There were improvements in the sub-scores; ADL, stigma and bodily discomfort and a trend towards worsening of communication.

\section{Speech intelligibility}

Pre- and post-operative assessments of speech intelligibility were performed for 49 consecutive patients. The pre-operative mean "on medication" intelligibility score was 97.3 (SD 7.8). The follow-up score "on medication and ON stimulation", had deteriorated to 84.4 (SD 27.2; $\mathrm{p}=0.0003$ ).

\section{Procedure and hardware related adverse events}

Among this consecutive series of 79 patients, superficial bleeding from a cortical vein was encountered in one patient during surgery. Once haemostasis had been achieved, a substantial quantity of CSF had leaked from the dural opening, the brain had fallen away from the skull and a decision was taken not to implant the permanent electrode. The procedure was, therefore, abandoned. Post-operative recovery was uneventful with no new neurological deficit and no haemorrhage visible on postprocedure scan. A further patient had their electrodes removed within the first 2 weeks post-operatively due to the development of a fluctuating encephalopathy with widespread white matter signal changes bilaterally following the course of the electrodes. The remaining "surgical" adverse events are documented in table 5 . One patient died from disseminated malignancy within 9 months of surgery and did not have follow-up scoring performed. Three patients underwent further surgery for their PD due to insufficient response from the first operation: re-positioning of one of the two STN electrodes in one patient with improvement in clinical effect, and additional bilateral globus pallidus internus (GPi) electrode placement in two patients more than 1 year after their STN DBS procedure 
Table 2 Comparisons of UPDRS III motor scores pre-operatively off- and on-medication, and post-operatively off and on medication/stimulation. UPDRS-Unified Parkinson's disease rating scale

\begin{tabular}{|c|c|c|c|c|c|}
\hline & $\begin{array}{l}\text { Baseline } \\
\text { Mean (SD) } \\
\text { Median } \\
\text { Range }\end{array}$ & $\begin{array}{l}\text { Follow-up } \\
\text { OFF Stim } \\
\text { Mean (SD) } \\
\text { Median } \\
\text { Range }\end{array}$ & $\begin{array}{l}\text { Follow-up } \\
\text { ON Stim } \\
\text { Mean (SD) } \\
\text { Median } \\
\text { Range }\end{array}$ & $\begin{array}{l}\text { Improvement from } \\
\text { Baseline to follow-up ON Stim } \\
\text { Mean (SD) } \\
\text { Median } \\
\text { Range } \\
\text { Mean Per cent (SD) } \\
\text { Median Per cent } \\
\text { Range } \\
\text { Summary data } \\
\text { (p value) }\end{array}$ & $\begin{array}{l}\text { Improvement from } \\
\text { follow-up OFF stim to ON stim } \\
\text { Mean (SD) } \\
\text { Median } \\
\text { Range } \\
\text { Mean Per cent (SD) } \\
\text { Median Per cent } \\
\text { Range } \\
\text { Summary data } \\
\text { (p value) }\end{array}$ \\
\hline $\begin{array}{l}\text { UPDRS III motor score } \\
\text { off-medication }\end{array}$ & $\begin{array}{l}51.5(14.9) \\
51 \\
19 \text { to } 88\end{array}$ & $\begin{array}{l}54.7(17.6) \\
51 \\
27 \text { to } 100\end{array}$ & $\begin{array}{l}23.8(11.2) \\
21 \\
7 \text { to } 59\end{array}$ & $\begin{array}{l}27.7(13.8) \\
27 \\
-3 \text { to } 67 \\
52.0 \%(20.9) \\
56.3 \% \\
-15.8 \% \text { to } 88.5 \% \\
\text { Improved } n=75 \\
\text { Worsened } n=1 \\
(p<0.0001)\end{array}$ & $\begin{array}{l}31.0(14.5) \\
30 \\
2 \text { to } 71 \\
55.5 \%(16.8) \\
57.7 \% \\
7.4 \% \text { to } 87.9 \% \\
\text { Improved } 76 \\
\text { Worsened } 0 \\
(p<0.0001)\end{array}$ \\
\hline $\begin{array}{l}\text { UPDRS III motor score } \\
\text { on-medication }\end{array}$ & $\begin{array}{l}14.6(7.7) \\
14 \\
2 \text { to } 39\end{array}$ & Not assessed & $\begin{array}{l}14.5(8.3) \\
12 \\
2 \text { to } 41\end{array}$ & $\begin{array}{l}0.0(7.97) \\
1.0 \\
-27 \text { to } 21 \\
-23.4 \%(91.2) \\
3.0 \% \\
-400 \% \text { to } 75 \% \\
\text { Improved } 37 \\
\text { Unchanged } 4 \\
\text { Worsened } 33 \\
\text { ( } p=0.72)\end{array}$ & Not assessed \\
\hline
\end{tabular}

because of persisting severe painful dyskinesias/dystonias. Neither of these patients has achieved good symptomatic control despite the additional surgery.

\section{DISCUSSION}

To the best of our knowledge, this is the largest published series of STN DBS performed in a single centre. Baseline patient demographics in the present study are similar to those operated in other series in terms of severity and duration of disease. ${ }^{16-18}$ Median overall improvement from baseline in the UPDRS III off-medication motor score was $56 \%$ (mean $52 \%$ ) and median improvement in PDQ39 Summary index was 7.9 points (mean 5.5 points). The low morbidity of the MRI-guided approach to surgery employed in this series demonstrates a high standard of safety while maintaining therapeutic efficacy.

There have been two large randomised controlled trials that evaluated the outcomes following DBS surgery in comparison to best medical treatment, one involving patients with STN DBS ${ }^{16}$ and the other with patients having DBS in either the STN or GPi. ${ }^{17}$ Among 78 patients with STN DBS aged $<75$ years, there was a mean improvement in the off-medication UPDRS III motor score of 19.6 points (15.1), equivalent to a $41 \%$ improvement, comparing baseline to post operative scores at 6 months. ${ }^{16}$ In parallel with this there was a 9.5-point (15.3) improvement in the PDQ39 summary index, equivalent to an overall mean improvement of $25 \%$ at 6 months, which is broadly similar to the overall mean improvement of $18 \%$ (median improvement 23.5\%) in our patients after 1 year of follow-up. This trial was conducted across 10 centres in Germany with STN targeting using either stereotactic MRI, ventriculography, MER or a combination of these techniques according to local surgical protocols. Adverse events in this series included one death from an intra-cerebral haematoma, one suicide 5 months after surgery and two infections at the stimulator site. The mean improvements in the clinical outcomes confirm the overall efficacy of the technique, although the wide $\mathrm{SD}$ in mean outcome, as in the current series, suggests substantial inter-patient variability in response.
The second large randomised controlled trial of $\mathrm{DBS}^{17}$ included 121 patients who received either STN DBS $(n=60)$ or GPi DBS ( $n=61)$. Of note is that this trial included at least $25 \%$ of the patients aged $>70$ years. All 13 participating sites were selected because they used MER to help in targeting. Among the group of patients as a whole, there was a 12.3-point improvement ( $95 \%$ CI -14.3 to -10.3 , SD not stated) in the UPDRS III off medication score at 6 months compared with baseline, equivalent to $29 \%$ improvement in scores. In addition, there was a 7.7-point improvement in the PDQ39 summary index with improvements in $7 / 8$ sub-domains. Among this group of patients, there was one patient death from intracerebral haemorrhage following the surgery and 16 infections related to the electrodes or neurostimulator requiring removal of the hardware.

In a meta-analysis of open label studies including 21 patient populations, ${ }^{18}$ the mean improvement following STN DBS in the UPDRS motor subscale was 27.6 points (equivalent to $52 \%$ improvement from baseline), and the mean improvement in quality-of-life was $34.5 \%$. These patients sustained intracranial haemorrhage in $3.9 \%$, infection in $1.7 \%$ and seizures in $1.5 \%$. In a further meta-analysis including 31 STN studies and totalling 565 patients, an overall improvement of $54 \%$ in the UPDRS III score was identified. ${ }^{19}$ The mean improvement in UPDRS III offmedication scores in the current series is thus in the average range when compared to that seen in either of the two large multi-centre trials ${ }^{16}$ and the meta-analyses of published data. $^{18} 19$

\section{Image-guided surgery and surgical adverse events}

The optimal target point within the visualised STN is as yet undefined. Our targeting strategy often resulted in the final target point being located a couple of millimetres posterolateral to the target point described by Bejjani et al ${ }^{14}$ (figure 1). Since the sensorimotor STN is thought to occupy the most superior, posterior and lateral portion of the nucleus, a more posterolateral target point within the STN may bring the electrode trajectory closer to the functional target. ${ }^{15}$ 
Table 3 Comparison of UPDRS part IV sub-scores pre-operatively and post-operatively

\begin{tabular}{|c|c|c|c|}
\hline UPDRS IV & $\begin{array}{l}\text { Baseline } \\
\text { Mean (SD) } \\
\text { Median } \\
\text { Range }\end{array}$ & $\begin{array}{l}\text { Follow-up ON Stim } \\
\text { Mean (SD) } \\
\text { Median } \\
\text { Range }\end{array}$ & $\begin{array}{l}\text { Improvement from } \\
\text { baseline to follow-up } \\
\text { ON stim } \\
\text { Mean (SD) } \\
\text { Median } \\
\text { Range } \\
\text { (p value) } \\
\text { Summary data }\end{array}$ \\
\hline Dyskinesia Duration & $1.49(0.85)$ & $0.81(0.84)$ & $0.69(0.9)$ \\
\hline $0=$ None & 1 & 1 & 1 \\
\hline $\begin{array}{l}1=1-25 \% \text { of day } \\
2=26-50 \% \text { of day } \\
3=51-75 \% \text { of day } \\
4=76-100 \% \text { of day }\end{array}$ & 0 to 4 & 0 to 4 & $\begin{array}{l}3 \text { to }-1 \\
(p<0.0001) \\
41 \text { improved } \\
25 \text { unchanged } \\
4 \text { worse }\end{array}$ \\
\hline Dyskinesia Disability & $1.11(1.11)$ & $0.44(0.81)$ & $0.65(1.2)$ \\
\hline $0=$ not disabling & 1 & 0 & 0 \\
\hline $\begin{array}{l}1=\text { mildly disabling } \\
2=\text { moderately disabling } \\
3=\text { severely disabling } \\
4=\text { completely disabling }\end{array}$ & 0 to 4 & 0 to 3 & $\begin{array}{l}3 \text { to }-2 \\
(p=0.0003) \\
31 \text { improved } \\
31 \text { unchanged } \\
8 \text { worsened }\end{array}$ \\
\hline $\begin{array}{l}\text { Dyskinesia Pain } \\
0=\text { No painful dyskinesias } \\
1=\text { slight } \\
2=\text { moderate } \\
3=\text { marked } \\
4=\text { severe }\end{array}$ & $\begin{array}{l}0.55(0.93) \\
0 \\
(0 \text { to } 3)\end{array}$ & $\begin{array}{l}0.32(0.72) \\
0 \\
(0 \text { to } 3)\end{array}$ & $\begin{array}{l}0.23(1.2) \\
0 \\
3 \text { to }-3 \\
(p=0.05) \\
\text { Improved }=19 \\
\text { Unchanged }=43 \\
\text { Worsened }=8\end{array}$ \\
\hline Early morning dystonia & $\begin{array}{l}\mathrm{No}=35 \\
\mathrm{Yes}=40\end{array}$ & $\begin{array}{l}\text { No }=46 \\
Y e s=27\end{array}$ & $\begin{array}{l}(p=0.06) \\
\text { Improved }=24 \\
\text { Unchanged }=35 \\
\text { Worsened }=12\end{array}$ \\
\hline Predictable 'offs' & $\begin{array}{l}\mathrm{No}=4 \\
\mathrm{Yes}=70\end{array}$ & $\begin{array}{l}\mathrm{No}=37 \\
\mathrm{Yes}=36\end{array}$ & $\begin{array}{l}(\mathrm{p}<0.0001) \\
\text { Improved }=33 \\
\text { Unchanged }=38 \\
\text { Worsened }=0\end{array}$ \\
\hline Unpredictable "offs" & $\begin{array}{l}\mathrm{No}=22 \\
\mathrm{Yes}=52\end{array}$ & $\begin{array}{l}\text { No }=57 \\
Y e s=16\end{array}$ & $\begin{array}{l}(\mathrm{p}<0.0001) \\
\text { Improved }=35 \\
\text { Unchanged }=34 \\
\text { Worsened }=2\end{array}$ \\
\hline Sudden "offs" & $\begin{array}{l}\mathrm{No}=34 \\
\mathrm{Yes}=40\end{array}$ & $\begin{array}{l}\text { No }=62 \\
\text { Yes }=11\end{array}$ & $\begin{array}{l}(\mathrm{p}<0.0001) \\
\text { Improved }=30 \\
\text { Unchanged }=37 \\
\text { Worsened }=4\end{array}$ \\
\hline $\begin{array}{l}\text { Proportion time off } \\
0=\text { None } \\
1=1-25 \% \text { of day } \\
2=26-50 \% \text { of day } \\
3=51-75 \% \text { of day } \\
4=76-100 \% \text { of day }\end{array}$ & $\begin{array}{l}1.82(0.72) \\
2 \\
1 \text { to } 4\end{array}$ & $\begin{array}{l}0.77(0.81) \\
1 \\
0 \text { to } 3\end{array}$ & $\begin{array}{l}1.1(1.1) \\
1 \\
4 \text { to }-2 \\
(p<0.0001) \\
\text { Improved }=49 \\
\text { Unchanged }=19 \\
\text { Worsened=3 }\end{array}$ \\
\hline
\end{tabular}

Post-operative MRI confirmation of electrode location confirms the reliability of MRI-guided electrode placement without MER. There is a paucity of publications that report on outcome of STN DBS using image-guided techniques. ${ }^{6}$ Our data demonstrate that MER may not be a pre-requisite to ensure well-placed electrodes that deliver a satisfactory clinical outcome. Importantly, the adverse event profile seen in this series compares very favourably with that reported in neurosurgical series that used MER, ${ }^{17}{ }^{18}{ }^{20-28}$ with no infection, haemorrhage or mortality associated with surgery, in the current series. The risk of symptomatic haemorrhage inevitably rises with increasing numbers of micro- or macro-electrode brain penetrations. ${ }^{20} 212329$ Furthermore, since MER significantly prolongs the procedure, we have been concerned that this potentially increases the risk of brain shift due to CSF leakage, which may paradoxically lower the precision of electrode placement as well as potentially increasing the risk of infection.

None of the patients in this series had visible haemorrhage on their post-operative imaging. The single patient that suffered a pulmonary embolus was treated with a vena cava filter, made
Table 4 Comparison of PD039 quality of life scores pre-operatively and post operatively

\begin{tabular}{|c|c|c|c|}
\hline & $\begin{array}{l}\text { Baseline } \\
\text { Mean (SD) }\end{array}$ & $\begin{array}{l}\text { Follow-up (ON-stim) } \\
\text { Mean (SD) }\end{array}$ & $\begin{array}{l}\text { Difference from baseline } \\
\text { to follow-up ON-stim }\end{array}$ \\
\hline & Median & Median & Mean (SD) \\
\hline & Range & Range & $\begin{array}{l}\text { Median } \\
\mathrm{p} \text { value }\end{array}$ \\
\hline \multirow[t]{3}{*}{ PD039 SI } & $30.2(13.0)$ & $24.7(15.0)$ & 5.5 points (17.3) \\
\hline & 28.2 & 23.8 & 7.9 points \\
\hline & 5.7 to 59.8 & 5.9 to 78.2 & $p=0.04$ \\
\hline \multirow[t]{3}{*}{ Mobility } & $50.8(22.0)$ & $40.1(25.1)$ & 10.7 points $(25.6)$ \\
\hline & 52.5 & 40.0 & 12.5 \\
\hline & 0 to 95 & 2.5 to 100 & $p=0.08$ \\
\hline \multirow[t]{3}{*}{ ADL } & $38.5(20.5)$ & $26.2(19.6)$ & 12.3 points $(23.6)$ \\
\hline & 37.5 & 20.8 & 12.5 \\
\hline & 4.2 to 75 & 0 to 87.5 & $p=0.002$ \\
\hline \multirow[t]{3}{*}{ Cognition } & $24.7(17.8)$ & $21.4(18.9)$ & 3.3 points $(20.1)$ \\
\hline & 18.8 & 18.75 & 6.3 \\
\hline & 0 to 68.8 & 0 to 87.5 & $p=0.12$ \\
\hline \multirow[t]{3}{*}{ Communication } & $23.0(19.6)$ & $28.9(21.7)$ & -5.9 points $(21.8)$ \\
\hline & 16.7 & 25 & -8.3 \\
\hline & 0 to 66.7 & 0 to 83.3 & $\mathrm{p}=0.08$ \\
\hline \multirow[t]{3}{*}{ Emotional } & $21.5(15.1)$ & $21.3(18.1)$ & 0.2 points (22.3) \\
\hline & 16.7 & 20.8 & 4.2 \\
\hline & 0 to 62.5 & 0 to 83.3 & $p=0.37$ \\
\hline \multirow[t]{3}{*}{ Stigma } & $26.4(23.0)$ & $14.9(17.5)$ & 11.5 points $(26.4)$ \\
\hline & 25.0 & 12.5 & 6.3 \\
\hline & 0 to 87.5 & 0 to 75 & $p=0.009$ \\
\hline \multirow[t]{3}{*}{ Social Support } & $12.9(16.3)$ & $13.7(19.8)$ & 0.8 points (17.2) \\
\hline & 8.3 & 8.3 & 0 \\
\hline & 0 to 66.7 & 0 to 83.3 & $\mathrm{p}=0.33$ \\
\hline \multirow[t]{3}{*}{ Bodily discomfort } & $43.5(24.5)$ & $31.0(22.9)$ & 12.5 points $(30.2)$ \\
\hline & 41.7 & 25 & 8.3 \\
\hline & 0 to 75 & 0 to 100 & $p=0.0009$ \\
\hline
\end{tabular}

a complete recovery and has an excellent response to DBS. Of the two patients that had peri-operative seizures, one had a history of previous seizures and the other did not. Neither patient is on long-term antiepileptic medication or has had seizures subsequently.

The number of surgical adverse events in our patients is very low. Nevertheless, the patient that required removal of electrodes warrants further discussion. Post-implant MR images revealed edema surrounding the entire intra-cerebral course of both electrodes. This lady had no history of allergy and did not show any evidence of nickel allergy when subsequently tested. The early post-operative course was unremarkable for the first few days but was followed by a fluctuating encephalopathy that did not respond to oral steroids. The electrodes were removed and were negative for Gram stain and fungal culture. Subsequent management of PD symptoms has been with medical therapies alone. We are unaware of any previous publications of this type of reaction to DBS surgery.

Table 5 Adverse events arising as a result of surgery in this series

\begin{tabular}{ll}
\hline Symptomatic haemorrhage & Nil \\
Asymptomatic haemorrhage & Nil \\
Pulmonary Embolus & 1 \\
Misplaced electrode & 1 \\
Pneumonia & 1 \\
Transient confusion/delirium & 7 \\
Seizure & 2 \\
Suicide & Nil \\
Scalp erosion & 1 \\
Infection & Nil \\
DBS Malfunction & Nil \\
Lead fracture & Nil \\
Lead migration & Nil \\
\hline
\end{tabular}


Several patients in our series developed dysarthria limiting stimulation settings to those that provide more modest motor improvements. Outcome measures of improvement in motor disability using "optimal" stimulation parameters are thus also influenced by other confounders. In a previous analysis of speech outcomes following STN DBS, we have reported that speech intelligibility deteriorates with stimulation among patients with electrodes situated in a more medial position. ${ }^{5} \mathrm{We}$, therefore, advocate imaging strategies that may further reduce the observed targeting error and improve reproducibility of electrode location with respect to the individual radiological anatomy.

This series confirms that MRI-guided STN DBS can lead to substantial mean improvements in motor disability of $\mathrm{PD}$ patients with improvement in quality of life. Reducing the risk associated with surgery through meticulous patient selection and optimal practice should serve as reassurance to patients with PD who may stand to benefit from this intervention but remain appropriately cautious about taking risks with their health.

Acknowledgements This work was supported by the Parkinson's Appeal registered charity 263064. The work was undertaken at UCLH/UCL who received a proportion of funding from the UK Department of Health's NIHR Biomedical Research Centres funding scheme.

Funding Other Funders: Parkinson's Appeal.

Competing interests The authors have no competing interests in the publication of this article.

Provenance and peer review Not commissioned; externally peer reviewed.

\section{REFERENCES}

1. Leksell L, Leksell D, Schwebel J. Stereotaxis and nuclear magnetic resonance. J Neurol Neurosurg Psychiatry 1985;48:14-18.

2. Limousin $\mathbf{P}$, Pollak $\mathrm{P}$, Benazzouz $\mathrm{A}$, et al. Effect of parkinsonian signs and symptoms of bilateral subthalamic nucleus stimulation. Lancet 1995;345:91-5.

3. Krack P, Batir A, van Blercom N, et al. Five-year follow-up of bilateral stimulation of the subthalamic nucleus in advanced Parkinson's disease. N Engl J Med 2003:349:1925-34.

4. Hariz MI, Rehncrona S, Quinn NP, et al. Multicenter study on deep brain stimulation in Parkinson's disease: an independent assessment of reported adverse events at 4 years. Mov Disord 2008;23:416-21.

5. Tripoliti E, Zrinzo L, Martinez-Torres I, et al. Effects of contact location and voltage amplitude on speech and movement in bilateral subthalamic nucleus deep brain stimulation. Mov Disord 2008;23:2377-83.

6. Patel NK, Plaha P, Gill SS. Magnetic resonance imaging-directed method for functional neurosurgery using implantable guide tubes. Neurosurgery 2007:61:358-65.

7. Williams-Gray $\mathbf{C H}$, Foltynie $\mathrm{T}$, Brayne $\mathrm{CE}$, et al. Evolution of cognitive dysfunction in an incident Parkinson's disease cohort. Brain 2007:130:1787-98.

8. Yorkston KM, Beukelman DR, Traynor CD. Articulatory adequacy in dysarthric speakers: a comparison of judging formats. J Commun Disord 1988;21:351-61.
9. Jenkinson C, Fitzpatrick R, Peto V, et al. The Parkinson's Disease Questionnaire (PDQ-39): development and validation of a Parkinson's disease summary index score. Age Ageing 1997;26:353-7.

10. Ashkan K, Blomstedt P, Zrinzo L, et al. Variability of the subthalamic nucleus: the case for direct MRI guided targeting. Br J Neurosurg 2007;21:197-200.

11. Hariz MI, Krack P, Melvill R, et al. A quick and universal method for stereotactic visualization of the subthalamic nucleus before and after implantation of deep brain stimulation electrodes. Stereotact Funct Neurosurg 2003;80:96-101.

12. Elias WJ, Sansur CA, Frysinger RC. Sulcal and ventricular trajectories in stereotactic surgery. J Neurosurg 2009;110:201-7.

13. Zrinzo L, van Hulzen AL, Gorgulho AA, et al. Avoiding the ventricle: a simple step to improve accuracy of anatomical targeting during deep brain stimulation. J Neurosurg 2009;110:1283-90

14. Bejjani BP, Dormont D, Pidoux B, et al. Bilateral subthalamic stimulation for Parkinson's disease by using three-dimensional stereotactic magnetic resonance imaging and electrophysiological guidance. J Neurosurg 2000:92:615-25

15. Yelnik J, Bardinet $E$, Dormont $D$, et al. A three-dimensional, histological and deformable atlas of the human basal ganglia. I. Atlas construction based on immunohistochemical and MRI data. Neuroimage 2007:34:618-38.

16. Deuschl G, Schade-Brittinger $C$, Krack $P$, et al. A randomized trial of deep-brain stimulation for Parkinson's disease. N Engl J Med 2006;355:896-908.

17. Weaver FM, Follett K, Stern M, et al. Bilateral deep brain stimulation vs best medical therapy for patients with advanced Parkinson disease: a randomized controlled trial. JAMA 2009;301:63-73.

18. Kleiner-Fisman G, Herzog J, Fisman DN, et al. Subthalamic nucleus deep brain stimulation: summary and meta-analysis of outcomes. Mov Disord 2006;21: S290-304.

19. Weaver F, Follett K, Hur K, et al. Deep brain stimulation in Parkinson disease: a meta analysis of patient outcomes. J Neurosurg 2005;103:956-67.

20. Hariz MI. Safety and risk of microelectrode recording in surgery for movement disorders. Stereotact Funct Neurosurg 2002;78:146-57.

21. Alkhani A, Lozano AM. Pallidotomy for parkinson disease: a review of contemporary literature. J Neurosurg 2001;94:43-9.

22. Hariz MI, Fodstad H. Do microelectrode techniques increase accuracy or decrease risks in pallidotomy and deep brain stimulation? A critical review of the literature. Stereotact Funct Neurosurg 1999;72:157-69.

23. Binder DK, Rau GM, Starr PA. Risk factors for hemorrhage during microelectrodeguided deep brain stimulator implantation for movement disorders. Neurosurgery 2005:56:722-32

24. Ben-Haim S, Asaad WF, Gale JT, et al. Risk factors for hemorrhage during microelectrode-guided deep brain stimulation and the introduction of an improved microelectrode design. Neurosurgery 2009;64:754-62.

25. Goodman RR, Kim B, McClelland S III, et al. Operative techniques and morbidity with subthalamic nucleus deep brain stimulation in 100 consecutive patients with advanced Parkinson's disease. J Neurol Neurosurg Psychiatry 2006:77:12-17.

26. Ory-Magne F, Brefel-Courbon C, Simonetta-Moreau M, et al. Does ageing influence deep brain stimulation outcomes in Parkinson's disease? Mov Disord 2007:22:1457-63.

27. Sansur CA, Frysinger RC, Pouratian N, et al. Incidence of symptomatic hemorrhage after stereotactic electrode placement. J Neurosurg 2007;107:998-1003.

28. Hamani C, Richter E, Schwalb JM, et al. Bilateral subthalamic nucleus stimulation for Parkinson's disease: a systematic review of the clinical literature. Neurosurgery 2005; 56:1313-21.

29. Deep Brain Stimulation Study Group. Deep-brain stimulation of the subthalamic nucleus or the pars interna of the globus pallidus in Parkinson's disease. $N$ Engl $J$ Med 2001;345:956-63. 